\title{
Uncertainty in water resources availability in the Okavango River basin as a result of climate change
}

\author{
D. A. Hughes ${ }^{1}$, D. G. Kingston ${ }^{2}$, and M. C. Todd ${ }^{3}$ \\ ${ }^{1}$ Institute for Water Research, Rhodes University, Grahamstown, South Africa \\ ${ }^{2}$ Department of Geography, University of Otago, P.O. Box 56, Dunedin, New Zealand \\ ${ }^{3}$ Department of Geography, University of Sussex, Brighton, UK
}

Received: 15 July 2010 - Published in Hydrol. Earth Syst. Sci. Discuss.: 16 August 2010

Revised: 21 February 2011 - Accepted: 9 March 2011 - Published: 16 March 2011

\begin{abstract}
This paper assesses the hydrological response to scenarios of climate change in the Okavango River catchment in Southern Africa. Climate scenarios are constructed representing different changes in global mean temperature from an ensemble of 7 climate models assessed in the IPCC AR4. The results show a substantial change in mean flow associated with a global warming of $2{ }^{\circ} \mathrm{C}$. However, there is considerable uncertainty in the sign and magnitude of the projected changes between different climate models, implying that the ensemble mean is not an appropriate generalised indicator of impact. The uncertainty in response between different climate model patterns is considerably greater than the range due to uncertainty in hydrological model parameterisation. There is also a clear need to evaluate the physical mechanisms associated with the model projected changes in this region. The implications for water resource management policy are considered.
\end{abstract}

\section{Introduction}

For the people living in the semi-arid climate of southwest Africa water scarcity provides a major stumbling block to increasing societal and individual well-being. One of the major water resources in this region is the Okavango River system. This transboundary river rises in the Angolan highlands, passes through the arid and semi-arid eastern parts of Namibia and drains into the famous Okavango delta of Botswana, an inland alluvial fan where the river terminates (Fig. 1). The Okavango River is one of the largest river systems in Africa and (the basin area upstream of the river delta is $\sim 165000 \mathrm{~km}^{2}$ ), drained by two major tributaries in the

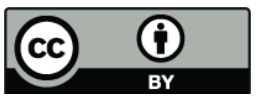

Correspondence to: D. A. Hughes

(d.hughes@ru.ac.za)
Angolan part of the catchment; the Cubango River and the Cuito River. A further tributary (Omatako River) draining part of Namibia joins the main river just upstream of the delta, but contributes almost no runoff due to the very low rainfall. The basin lies within a sharp northeast-southwest precipitation gradient across southern Africa. The climate of the basin region is characterized by a pronounced annual cycle with a single wet season of October to March (precipitation $\sim 6 \mathrm{~mm} \mathrm{day}^{-1}$ ). The Okavango delta wetland system is maintained by annual flooding of the Okavango River creating the world's second largest inland wetland region: a unique, dynamic mosaic of habitats with exceptionally high beta diversity. It is one of the WWF's top 200 ecoregions of global significance and is one of the world's larger Ramsar sites.

Currently, the Okavango River basin is one of the least developed river basins in Africa. Nevertheless, the basin represents an important water resource for all three countries, but for different reasons. Moreover, socio-economic needs of a growing population are likely to result in greater development of water resources. Within Angola there is very little existing development apart from some small abstractions for domestic and irrigation supplies to rural communities. While future developments in Angola are quite uncertain, there is a recognized potential for expanded irrigation as well as hydropower development which may have consequences for water availability in downstream countries (Andersson et al., 2006; Pinheiro et al., 2003; Ellery and McCarthy, 1994) and potentially negative environmental consequences (Green Cross International, 2000; Mbaiwa, 2004). Likewise, future development in the semi-arid downstream sections of the basin must be considered. There are some existing abstractions for irrigation purposes near Rundu (Namibia) and these are expected to be further developed in the future. There are also plans for a pipeline to transfer water to the central part of Namibia near Windhoek (Pinheiro et al., 2003). Within

Published by Copernicus Publications on behalf of the European Geosciences Union. 


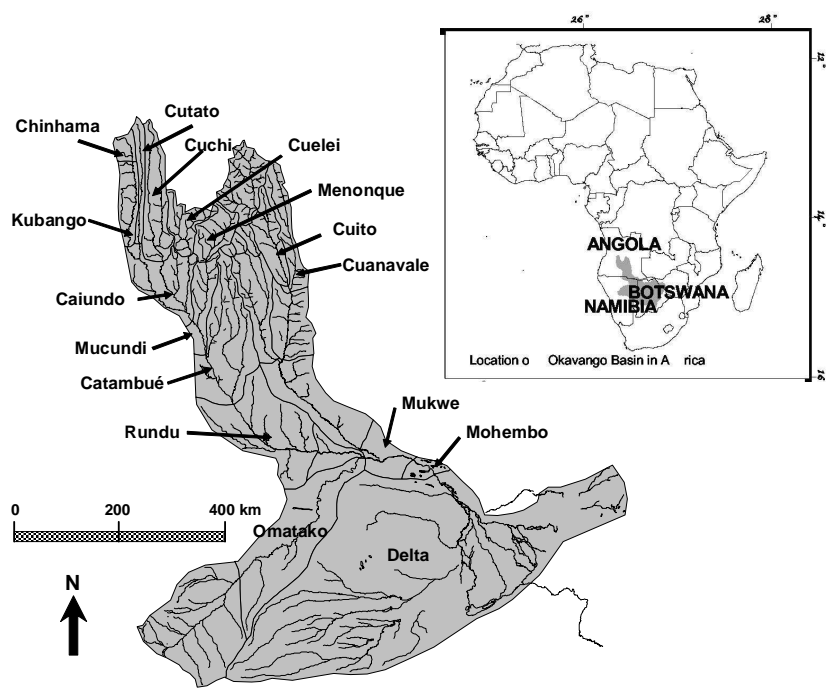

Fig. 1. Okavango River showing the modeled sub-basins. Most of the gauged sub-basins are labeled with arrows and the insert shows the location within Africa.

Botswana the main resource issues are associated with the functioning of the delta, an extremely important source of tourism revenue for the country. The seasonal flooding regime of the river represents an important component of the ecological functioning of the delta (Wolski et al., 2006; Wolski and Murray-Hudson, 2008) and is also important in sustaining the livelihoods of many of the people living in the delta.

Some of the possible water resource developments within the basin have the potential to be in conflict with each other and many of these conflicts could be exacerbated by future changes in the amount or patterns of variation of the available water resource that may result from climate change. Indeed, the basin has been identified by the World Water Assessment as having the potential for water-related disputes (Wolf et al., 2003). It is therefore important to establish an approach that can be used to assess the possible changes as a basis for resolving the potential conflicts and developing appropriate management strategies. This paper represents an assessment of climate change scenarios on the water budget and water resources availability in the Okavango River basin.

In this study, the Okavango River was one of a number of river systems for which a unified climate change impact assessment was conducted, coordinated under the QUESTGlobal Scale Impacts project, funded by the UK Natural Environment Research Council (NERC). The work represents an extension of the work that was completed during two previous EU projects designed to establish and evaluate water resource estimation tools that are appropriate for this data scarce region. The first project (WERRD - Water and Ecosystem Resources in Regional Development) applied the Pitman monthly rainfall-runoff model to simulate the natural hydrology of the basin (Andersson et al., 2003; Hughes et al., 2006; Wilk et al., 2006) and investigated various scenarios of climate change and development (Andersson et al., 2006). The second project (TWINBAS - Twinning European and third countries river basins for development of integrated water resources management methods) was focused on further refinement of the rainfall-runoff model calibration and the extent to which the outputs from the model could be used for water resources decision making.

\section{Data and methods}

\subsection{Modeling the hydrology of the Okavango basin}

The Okavango basin can be effectively divided up into four main components; the Cubango River (drainage area of approximately $99800 \mathrm{~km}^{2}$ ), the Cuito River (approximately $61600 \mathrm{~km}^{2}$ ) and the Omatako River (approximately $58800 \mathrm{~km}^{2}$ but with almost no flow contributions), and the lower parts of the main Okavango River $\left(8600 \mathrm{~km}^{2}\right)$ which lies downstream of the confluence of the three tributaries and above the "panhandle" part of the delta (Fig. 1). The region as a whole is data-sparse, and hydro-meteorological observations have declined in recent decades (Wilk et al., 2006), presenting major challenges for hydrological model development (Hughes et al., 2006). Within the Cubango River tributary there are 10 sub-basins for which some stream flow gauging data are available, most having short records that started in about 1963 and ended in 1974. The gauge at Rundu has a longer record that started in 1945 and is still operational. There are far less stream flow data available for the Cuito River. However, the discharge is gauged at Mukwe $\left(18.04^{\circ} \mathrm{S}, 21.42^{\circ} \mathrm{E}, 1949\right.$ to 1998$)$ representing the runoff for the entire Okavango basin, including both the Cubango and Cuito tributaries. Accordingly our analysis of climate change is based on simulations of river flow at Mukwe. The available information for rainfall over the basin using groundbased observations (Wilk et al., 2006) is relatively sparse with data lengths that are similar to many of the stream flow gauges (early 1960s to mid-1970s). Information about potential evaporation data is similarly lacking.

The two main tributaries have very different runoff responses to rainfall. Figure 2 shows the non-dimensional 1month annual flow duration curves (FDCs) for 5 of the gauging stations. Caiundo $\left(38420 \mathrm{~km}^{2}\right)$ and Rundu $\left(95642 \mathrm{~km}^{2}\right)$ stations are located in the middle and lower reaches of the Cubango River, respectively and both have quite steep FDCs. Cuanavale $\left(23337 \mathrm{~km}^{2}\right)$ is located in the middle to upper reaches of the Cuito River and has a very flat FDC. Menongue $\left(5623 \mathrm{~km}^{2}\right)$ is in the upper reaches of the Cubango River but on the eastern side of the basin and demonstrates characteristics which are closer to those of the Cuito basin. The flow records at Mohembo $\left(228778 \mathrm{~km}^{2}\right)$ represent an integration of the total basin response and illustrates the dominance of the Cubango River. 


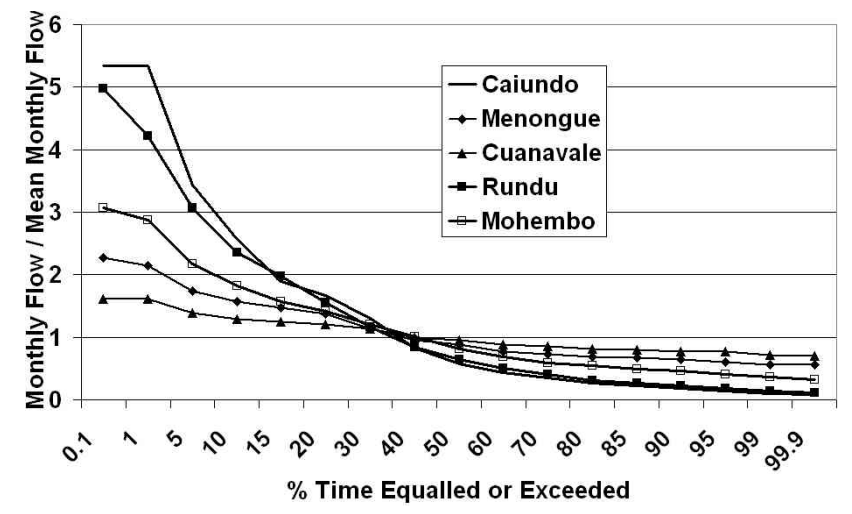

Fig. 2. 1 month annual flow duration curves for 5 of the gauged tributaries within the Okavango basin.

The rainfall-runoff response characteristics are mainly a reflection of the differences in physical basin characteristics rather than any differences in the seasonality or amounts of rainfall, which are very similar for the two headwater areas. The main reason for the different responses appear to be related to geology (eastern areas are dominated by deep Kalahari sands whereas western tributaries are underlain by less permeable Karoo and Damara group rocks) and differences in vegetation (eastern areas are more heavily forested whereas western areas are dominated by savanna) (Mendelsohn and el Obeid, 2004). The existence of a much broader valley floor, many more wetland areas and secondary channels in the Cuito River, compared to the Cubango River (Fig. 3), could also have a substantial impact on the transmission of upstream flows and therefore the shape of the FDCs.

\subsubsection{The Pitman hydrological model}

The details of the monthly time-step Pitman model structure (Fig. 4) can be found in Hughes et al. (2006) and are not repeated here. The model can be described as a conceptual type model which includes all of the main components of the hydrological cycle (with the exception of any processes related to snow and ice which are not relevant to most southern African basins). There are 19 main parameters that are used to determine the natural sub-basin water dynamics and the climatic inputs consist of time series of precipitation and potential evaporation. The version that is used in this study operates as a semi-distributed model with each sub-basin having separate parameter sets and input time series. The parameters can be divided up into groups on the basis of the model components:

- RDIST used to distribute the monthly rainfall depths into 4 periods.

- Interception parameters (PI1 and PI2 mm) for two vegetation types.
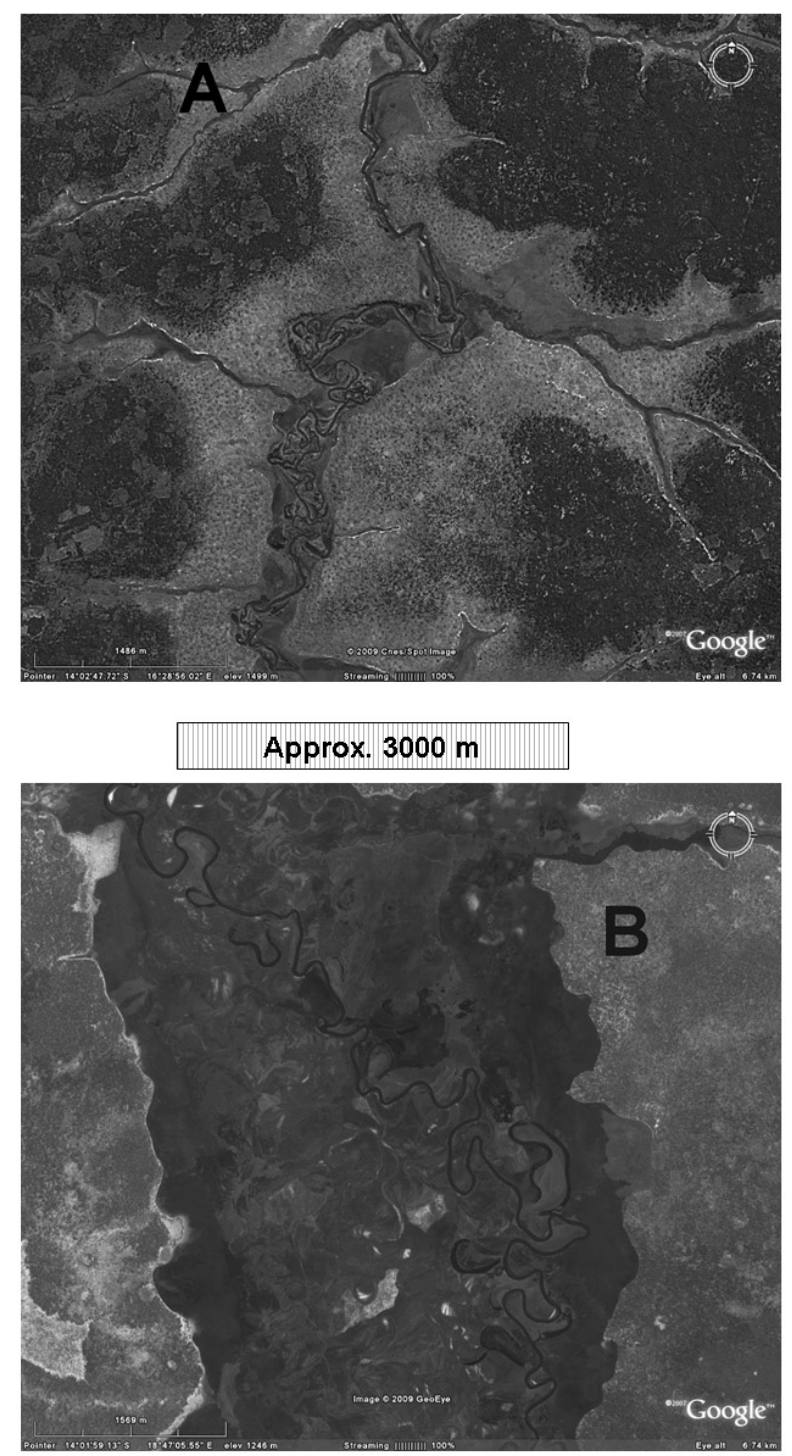

Fig. 3. Google Earth images of the Cubango (A) and Cuito (B) rivers at locations where their catchment areas are similar. Eye altitude is $6.74 \mathrm{~km}$ in both cases.

- Three parameters that determine the shape of the triangular sub-basin absorption (infiltration) function (ZMIN, ZAVE and ZMAX mm month ${ }^{-1}$ ).

- ST mm, defining the maximum unsaturated zone storage capacity.

- FT (mm month ${ }^{-1}$ ) and POW used to define the runoff from unsaturated zone storage.

- GW (mm month ${ }^{-1}$ ) and GPOW used to define the groundwater recharge from unsaturated zone storage.

- R used to determine (together with monthly potential evaporation) the rate of evapotranspiration loss from unsaturated zone storage. 


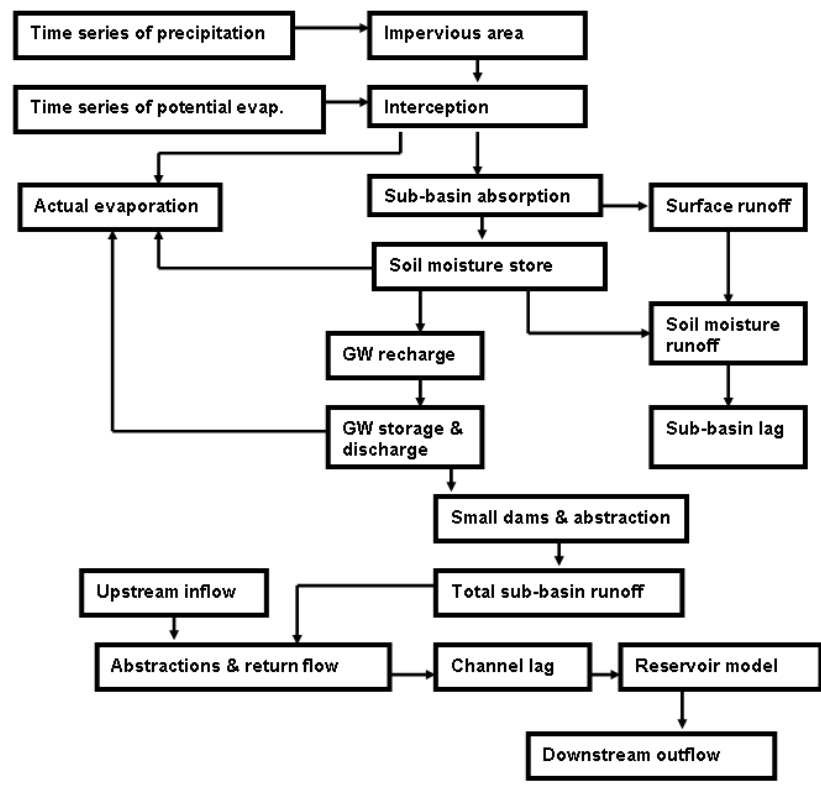

Fig. 4. Flow diagram of the Pitman monthly hydrological model.

- Drainage density (DDENS $\mathrm{km} \mathrm{km}^{2}$ ), storativity (S), transmissivity $\left(\mathrm{T} \mathrm{m}^{2} \mathrm{~d}^{-1}\right)$, regional groundwater gradient (Slope) and riparian evaporation loss factor (RFACT $\%)$ are used to determine the groundwater response dynamics.

- TL and CL (months) are the sub-basin and channel routing time lags.

The model also contains additional components (and parameters) to simulate reservoirs (storage, releases and abstractions), abstractions from run-of-river flows and transfers of water in and out of sub-basins. However, no details are given here as these parts of the model are not used in this study.

Two software versions of the model are available, the first of which operates with a single set of parameters for each sub-basin and generates a single output. In the second version, the parameter inputs can be defined as frequency distributions (normal, log-normal or uniform) and ensembles (typically 1000) of model results are generated using Monte Carlo sampling procedures. Where observed data are available, the outputs include calculations of several objective functions used to compare the simulated ensembles with the observed flow time series. This approach can be used to assist in calibration by exploring the results of many different parameter combinations. It can also be used to generate ensembles that represent the uncertainty in the selection of optimal parameter sets (Beven and Freer, 2001).

The Pitman model has been used extensively in the southern Africa region for both research-based studies and practical water resources estimation. Recent work (Kapangaziwiri and Hughes, 2008) suggests that the parameters have physical meaning and can be interpreted using measurable physical basin properties. However, the large number of parameters also suggests that parameter values are difficult to identify in the absence of detailed information about basin properties and that the calibration of the model suffers from problems of equifinality or non-uniqueness of different parameter sets (Beven, 2006).

\subsubsection{Model calibration for baseline conditions}

The previous calibrations of the model (Andersson et al., 2003; Hughes et al., 2006) were based upon historical rainfall data interpolated from rain gauges that were active during the period 1960 to about 1972 and that are no longer operational. These previous studies already identified the problems of simulating other periods using rainfall data that are not compatible with the historical gauge data and it is widely accepted that hydrological model parameter sets cannot be considered independent of the rainfall inputs (Oudin et al., 2006). If the model is to be used to simulate the effects of future climate patterns it is important that the rainfall data used to establish the model (i.e. calibration) are consistent with the rainfall data that are used within the future climate model runs. The approach used to translate the outputs from the climate model projections of future climate into time series of rainfall data suitable for input into the hydrological model is explained in Sect. 2.2 and in Todd et al. (2010) and it is important that the Pitman model is set up using rainfall data that are consistent with this approach. It was therefore necessary to re-calibrate the Pitman model using the same gridded rainfall data that was used in the generation of the future climate scenarios. In the first instance the CRU (Climate Research Unit) TS3.0 half-degree gridded data (Mitchell and Jones, 2005) covering the period January 1961 to December 1990 were used, but these were found to generate excessive flows in 1967 and deficient flows in several of the other years of the calibration period (Fig. 5). These effects could not be removed by further parameter calibration without adversely affecting simulations in other years. While an attempt was made to adjust the CRU rainfall using the frequency characteristics of the historical gauge rainfall data from individual stations, it was recognized that it would be very difficult to include a similar adjustment in the future climate scenarios based on climate model outputs. An alternative gridded data set (UDEL) is available from the University of Delaware, based on the Legates and Willmott (1990) data (for full description see http://climate.geog.udel. edu/ climate/html_pages/README.lw.html). The analysis (Fig. 5) indicates that these data give slightly better simulations (after calibration) at Rundu than the CRU data. However, the extreme rainfall in 1967 is still present. Figure 6 compares the simulation results at the downstream part of the basin (Mukwe) for the whole period and suggests that the use of the UDEL data give similar, or better, quality simulations for the calibration period (1961 to 1972) than the CRU 


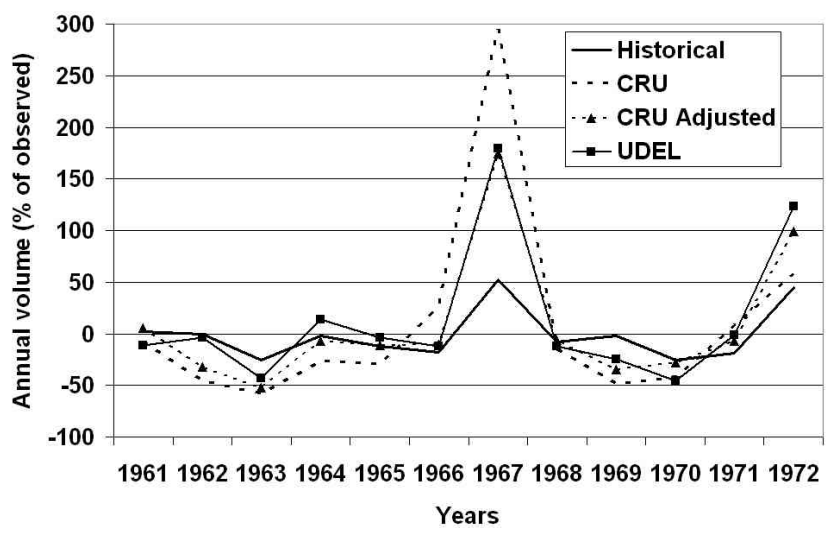

Fig. 5. Deviations (\%) from observed of simulated mean annual flow volumes of the Okavango River at Rundu (using the main calibration period of 1961 to 1972) based on different input rainfall data. "Historical" data are based on local gauges.

data after adjustment. However, there is a major problem of under-simulation during the late 1970s and throughout most of the 1980s.

The final hydrological model parameter sets were based on progressive calibration from the gauged headwater subbasins (Chinhama, Cutato, Cuchi, Cuelei and Menongue), through the gauged sub-basins in the middle parts of the basin (Cubango, Caiundo, Mucundi, Catambué, Rundu, Cuito and Cuanavale) to the lower gauges at Mukwe and Mohembo. The calibration starting point was based on the previous parameter sets manually calibrated using the gauged rainfall data (Hughes et al., 2006). After some initial exploratory runs using the ensemble generation version of the model, it was decided to fix some parameters with regional patterns of variation similar to those used in the earlier studies (RDIST, PI1, PI2, ST, POW, GPOW, R, DDENS, T, $\mathrm{S}$, Slope and RFACT). The remaining parameters (ZMIN, ZAVE, ZMAX, FT and GW) were treated as uncertain using ranges between likely maximum and minimum values to define a uniform distribution, after which 1000 hydrological simulation ensembles were generated. This approach was adopted to remove some of the problems of equifinality while ensuring that some uncertainty remains in the final calibrated parameter sets. The ranges of the uncertain parameters were established to ensure that they included the best possible fit to the available observed data (Table 1) using four objective functions and to ensure that there is no systematic bias in the simulated volumes within the 1000 member ensemble (i.e. the range of values for \% Error $\{\mathrm{Q}\}$ were approximately evenly distributed around 0 ). Table 1 indicates that these objectives were mostly achieved although the Cuanavale simulations are somewhat biased toward higher flows than observed, while those for Mukwe are biased toward negative errors.

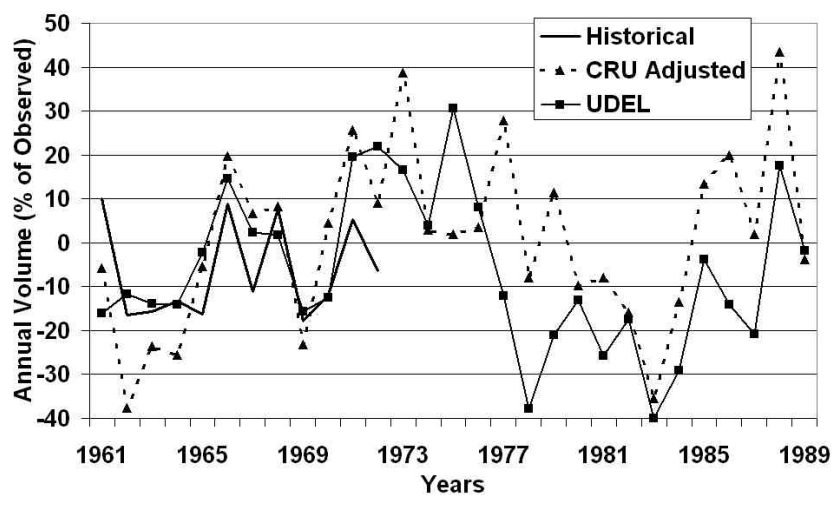

Fig. 6. Deviations (\%) from observed of simulated mean annual flow volumes of the Okavango River at Mukwe (using the whole baseline period of 1961 to 1990) based on different input rainfall data. "Historical" data are interpolated local gauges, described in Wilk et al. (2006).

Comparisons between the results presented in Table 1 and those given in Hughes et al. (2006) indicate that the revised simulations have improved for three (Cuchi, Cuelei and Catambué) of the sub-basins based on the CE $\{\mathrm{Q}\}$ and $\mathrm{CE}\{\operatorname{Ln}(\mathrm{Q})\}$ values for the best simulations within the 1000 member ensemble. In most cases the revised results are marginally poorer, while for Rundu and Mukwe they are noticeably poorer. However, this is mainly related to the fact that the observed data period used for comparison in Hughes et al. (2006) was confined to the calibration period (1961 to 1972), while in this study it has been extended to all available observed data (1961 to 1990). Figure 7 illustrates that the uncertainty bounds are relatively narrow and this is a consequence of the use of the observed data in the headwater subbasins resulting in a well determined model during the period when local rainfall data are available. However, Fig. 7 also illustrates that the simulations are not very representative of the seasonal distribution at Mukwe, and the model suggests a greater response to the early wet season rainfall than the observed data. This effect is not apparent for the headwater basins during the calibration period and various attempts to re-calibrate the parameter sets and remove this early season bias did not meet with any success. It is concluded that the gridded UDEL rainfall data are not very representative of real catchment rainfall patterns during the period after the early 1970s when most of the local gauges were closed. The main problem appears to be associated with the general under-estimate of rainfall in the peak months evident from Figs. 6 and 7.

\subsection{Climate change scenarios}

Following calibration of the Pitman hydrological model for the baseline historical period, the model was used for simulations of hydrological responses to future climate. To this 
Table 1. Calibration results including uncertainty in some of the main water balance parameters, the two values represent the highest and lowest values for each objective function amongst all 1000 simulation ensembles.

\begin{tabular}{lrrrr}
\hline \multirow{2}{*}{ Sub-basin } & \multicolumn{4}{c}{ Objective Function } \\
\cline { 2 - 5 } & $\mathrm{CE}\{\mathrm{Q}\}$ & $\mathrm{CE}\{\operatorname{Ln}(\mathrm{Q})\}$ & \% Error $\{\mathrm{Q}\}$ & \% Error $\{\ln (\mathrm{Q})\}$ \\
\hline Chinhama & $0.579: 0.708$ & $0.656: 0.797$ & $-7.7: 6.6$ & $-3.6:-0.3$ \\
Cutato & $0.406: 0.613$ & $0.440: 0.604$ & $-9.0: 7.6$ & $-3.1: 0.6$ \\
Cuchi & $0.359: 0.664$ & $0.617: 0.758$ & $-10.7: 13.5$ & $-2.5: 2.0$ \\
Cuelei & $0.517: 0.523$ & $0.523: 0.774$ & $-12.4: 14.4$ & $-4.7: 2.2$ \\
Menonque & $0.256: 0.561$ & $0.524: 0.646$ & $-10.8: 12.7$ & $-2.7: 3.0$ \\
Kubango & $0.539: 0.681$ & $0.587: 0.730$ & $-8.2: 6.9$ & $-1.9: 0.9$ \\
Caiundo & $0.507: 0.667$ & $0.591: 0.696$ & $-7.3: 5.7$ & $-2.0: 0.0$ \\
Mucundi & $0.485: 0.654$ & $0.599: 0.711$ & $-5.6: 6.3$ & $-1.2: 0.4$ \\
Catambué & $0.744: 0.829$ & $0.745: 0.821$ & $-6.3: 6.2$ & $-1.6: 0.1$ \\
Rundu & $0.546: 0.633$ & $0.687: 0.739$ & $-9.6: 3.2$ & $-1.2: 0.6$ \\
Cuito & $0.308: 0.494$ & $0.306: 0.489$ & $-6.6: 8.9$ & $-0.9: 1.1$ \\
Cuanavale & $0.111: 0.636$ & $0.326: 0.657$ & $-3.5: 11.9$ & $-0.6: 1.9$ \\
Mukwe & $0.580: 0.648$ & $0.709: 0.758$ & $-8.1: 0.5$ & $-1.1: 0.0$ \\
Mohembo & $0.451: 0.591$ & $0.684: 0.730$ & $-4.5: 4.1$ & $-0.5: 0.7$ \\
\hline
\end{tabular}

Notes: The objective functions are the Coefficient of Efficiency (Nash and Sutcliffe, 1970) based on ordinary values, CE $\{\mathrm{Q}\}$ and log transformed values, CE $\{$ Ln(Q) $\}$ and the \% errors in mean monthly flow relative to the observed flows using ordinary values, \% Error $\{\mathrm{Q}\}$ and $\log$ transformed values, \% Error (ln $(\mathrm{Q})\}$. The objective functions are based on all available observed flow data at each individual gauge.

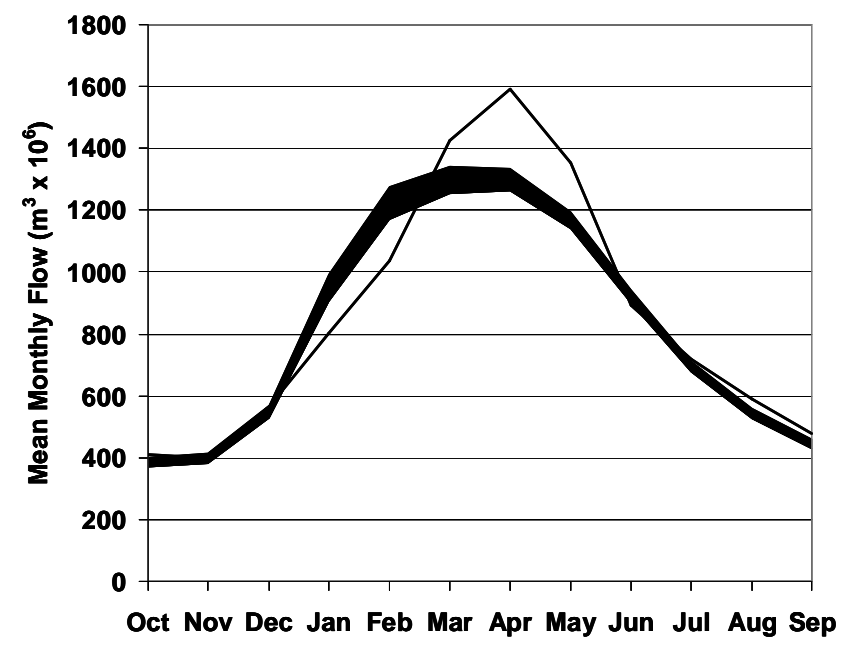

Fig. 7. Seasonal distributions of mean monthly observed flow (thin line) and the envelope of the 1000 member ensemble of simulated flow for the Okavango River at Mukwe for the baseline period.

end, the Pitman hydrological model was forced with an ensemble of future climates, in order to represent uncertainty associated with both structural uncertainty in Global Climate Models (GCMs) and uncertainty in the magnitude of future global warming (see Todd et al., 2010). Moreover, the hydrological simulations involved further ensemble simulations to represent uncertainty in hydrological model parameterization. A unique feature of this project is the application of a set of 'prescribed warming' scenarios in which the future climate associated with specific levels of future global mean temperature increases are defined from multiple GCMs. A total of $7 \mathrm{GCMs}$ were used in the assessment of climate scenarios and based on scenarios of $2{ }^{\circ} \mathrm{C}$ warming relative to global mean temperature from the 1961-1990 baseline period. The models used were a subset of the CMIP-3 set (Meehl et al., 2007), and comprised CCCMA CGCM31, UKMO HadCM3, CSIRO Mk30, UKMO HadGEM1, IPSL CM4, MPI ECHAM5 and the NCAR CCSM30. These models were chosen on the basis of (i) a subjective evaluation of model quality and (ii) the use of the model (or its predecessors) in previous impact assessments (Todd et al., 2010). The outputs from the UKMO HadCM3 model for scenarios of prescribed global warming of $1,2,3,4,5$ and $6^{\circ} \mathrm{C}$ have also been included in the analysis. Future climate scenarios for temperature and precipitation were generated using the ClimGen pattern-scaling technique described in Todd et al. (2010), developed under the UK QUEST-GSI project and available at http://www.cru.uea.ac.uk/_timo/climgen/. It should be noted that unlike the other studies conducted in the QUEST-GSI project and summarised in Todd et al. (2010), the UDEL historical climate data were used in the Okavango study instead of the CRU TS3.0, for reasons described above. In addition, this study also incorporated an assessment of uncertainty associated with the estimation of the hydrological parameters. The model parameter values (and their uncertainty distributions, represented by a $1000 \mathrm{mem}$ ber ensemble) used for the baseline simulations were retained for the climate change scenarios. As such, a grand ensemble of hydrological simulations was constructed representing uncertainty in both future climate and hydrological model parameters. 


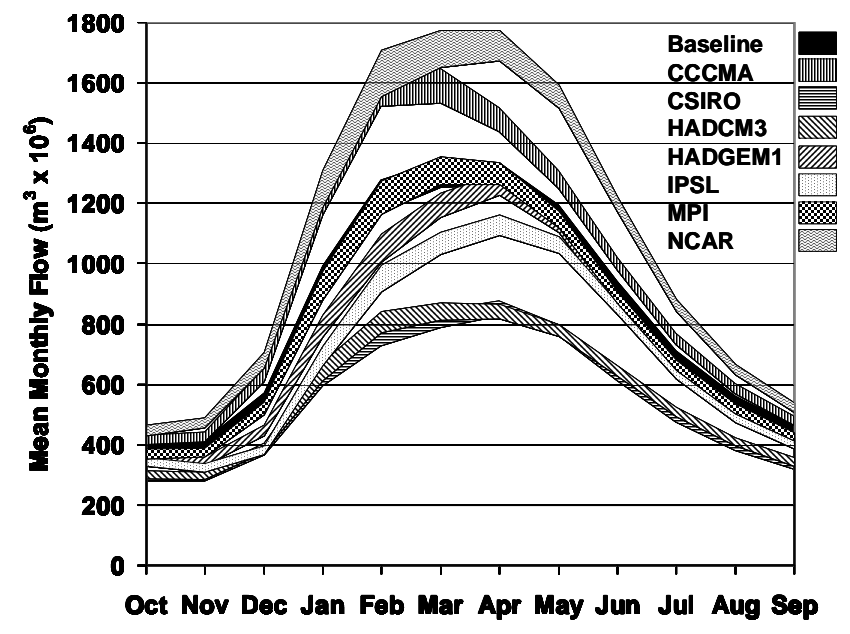

Fig. 8. Mean calendar monthly flow for the Okavango River at Mukwe based on a 1000 member ensemble simulation for the 7 GCMs, compared to the baseline simulation.

By dividing the climate change in a particular variable at each grid cell by global mean temperature change the "standardised" pattern of climate change in that variable per unit global mean temperature increase $(\Delta T)$ is defined. This "pattern scaling" procedure allows calculation of the spatial pattern of climate change in any variable, associated with any given global mean temperature change (i.e. prescribed warming), assuming a linear dependence of change in $\Delta T$. The standardised climate change patterns are calculated separately for each month to preserve the seasonal information, and are all interpolated statistically onto a $0.5 \times 0.5^{\circ}$ global grid. Within ClimGen these patterns are used to create gridded fields of monthly data with which to force hydrological models. The change pattern is used to perturb a historical dataset to ensure minimal bias with respect to observations, a necessary condition for running impact models calibrated with respect to historical observations.

Calculation of evaporation demand inputs to the model are based on 12 fixed mean monthly potential evaporation values (MPET ${ }_{j}$, for $j=1$ to 12$)$ and time series of fractions $\left(\mathrm{PF}_{i j}\right.$, for $i=1$ to number of years) that define the variations in potential evaporation from the long-term monthly mean. Thus, the potential evaporation used for any month in the model time series is estimated from Eq. (1).

$\mathrm{PET}_{i j}=\mathrm{MPET}_{j} \times \mathrm{PF}_{i j}$

The MPET $_{j}$ values used are the same as those used in the earlier studies (Hughes et al., 2006) and based on the limited available records. PF values for the baseline period are based on CRU TS 3.0 monthly temperature values and are estimated from Eq. (2), where $\mathrm{BT}_{i j}$ values are the estimated mean temperatures for year $i$ and month $j$ and $\mathrm{MBT}_{j}$ values

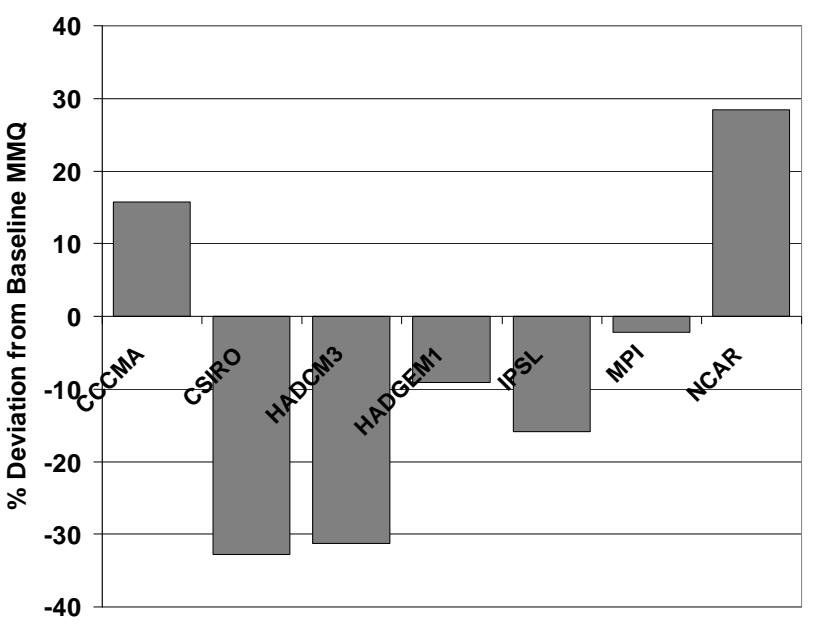

Fig. 9. Deviations, relative to the baseline conditions, of mean monthly flow of the Okavango River at Mukwe for the total simulation period for the 7 GCMs.

are the means for each calendar month for the whole baseline simulation period.

$\mathrm{PF}_{i j}=\mathrm{BT}_{i j} / \mathrm{MBT}_{j}$

The PF values for each of the climate change scenarios are calculated from equation 3 where $\mathrm{CC}_{k} \mathrm{PF}_{i j}$ and $\mathrm{CC}_{k} T_{i j}$ are the fractions and mean temperatures for climate change scenario $k$ (i.e. for each of the different GCMs).

$\mathrm{CC}_{k} \mathrm{PF}_{i j}=\mathrm{CC}_{k} T_{i j} / \mathrm{MBT}_{j}$

This formulation represents a very simple approach for linking evaporative demand to temperature changes and, for mean temperature values typical of the study region, suggests a sensitivity of PET to temperature of $\sim 5 \% \mathrm{C}^{-1}$. This value is within the range calculated using various widelyused empirical PET methods (Kingston et al., 2009), and appears to be satisfactory based on the model calibration process (Hughes et al., 2006). In recognition of this, sensitivity analyses were conducted based on PET calculations using the Hargreaves formula (Allen et al., 1998). This method was chosen because there were insufficient data for calculation of PET using the Penman-Monteith method, and the FAO have recommended that the Hargreaves method is used in such situations (Allen et al., 1998). Results of this sensitivity analysis are presented in Table 2 and described below.

\section{Results and discussion}

Figure 8 illustrates the results of generating an ensemble of 1000 simulations for each of the 7 GCMs (using the simple potential evaporation demand approach) for the $2{ }^{\circ} \mathrm{C}$ prescribed global warming scenario, compared with the baseline scenario at Mukwe. The bands represent the upper and 
Table 2. Mean monthly runoff of the Okavango river at Mukwe $\left(\mathrm{m}^{3} \times 10^{6}\right)$, and changes with respect to baseline conditions associated with a $2{ }^{\circ} \mathrm{C}$ global warming using the simple potential evaporation approach versus the use of the Hargreaves estimation equation. The values are based on the mean hydrological parameter uncertainty ensemble in all cases.

\begin{tabular}{lrrrr}
\hline \multirow{2}{*}{ GCM } & \multicolumn{2}{c}{ Mean Monthly runoff $\left(\mathrm{m}^{3} \times 10^{6}\right)$} & \multicolumn{2}{c}{ \% change from baseline } \\
\cline { 2 - 5 } & Simple approach & Hargreaves & Simple approach & Hargreaves \\
\hline CCCMA & 953.8 & 983.0 & 15.8 & 19.4 \\
HadCM3 & 566.7 & 576.6 & -32.6 & -30.0 \\
CSIRO & 554.9 & 560.4 & -31.2 & -31.9 \\
HadGEM1 & 748.9 & 772.9 & -9.0 & -6.1 \\
IPSL & 693.5 & 718.2 & -15.8 & -12.8 \\
MPI & 805.4 & 833.3 & -2.2 & 1.2 \\
NCAR & 1057.8 & 1119.6 & 28.5 & 36.0 \\
\hline
\end{tabular}

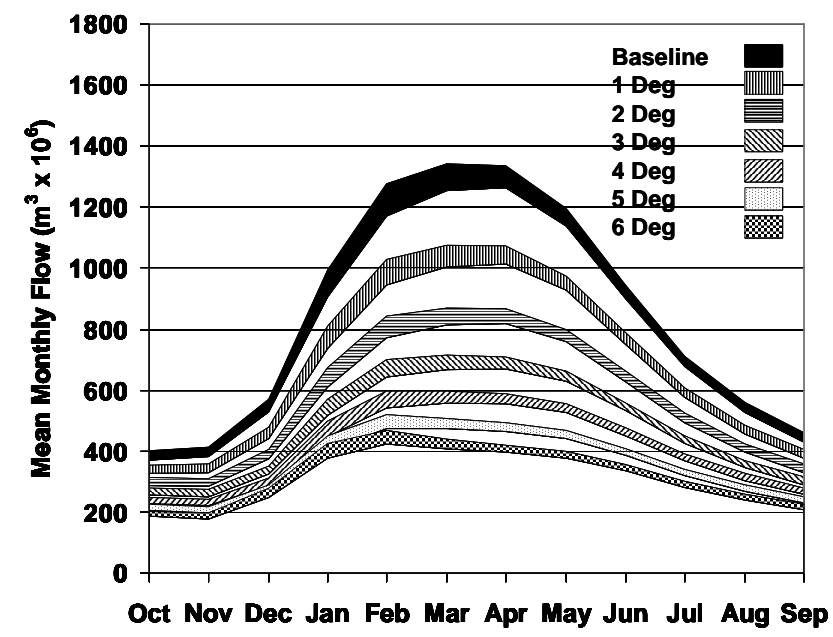

Fig. 10. Mean calendar monthly flow for the Okavango River at Mukwe based on a 1000 member ensemble simulation for the 6 HADCM3 scenarios, compared to the baseline simulation.

lower limits of the hydrological parameter ensemble simulations. Figure 9 shows the percentage deviations (from the baseline simulation) of mean monthly flow for the total simulation period for each of the GCMs whereas Fig. 10 shows the ensemble results for the different global warming scenarios using HadCM3. A number of important results emerge from this.

1. It is clear that simulations indicate very substantial changes to the magnitude of river flows in the Okavango River basin associated with a $2{ }^{\circ} \mathrm{C}$ global warming. For five out of the seven GCMs, there are changes in excess of $10 \%$ in mean annual river flow and for three models, in excess of $30 \%$.

2. These changes in mean annual flow must be placed in the context of the relatively high variability in river flow in the Okavango (Jury, 2010). The standard deviation of annual flow is $22 \%$ of the mean (1961-1990), such that the projected changes associated with a $2{ }^{\circ} \mathrm{C}$ global warming exceed the standard deviation for three of the seven GCM scenarios considered here. Of these, there are two GCMs scenarios (HadCM3, CSIRO), however, for which the simulated mean annual flow is below the $10 \%$ percentile of the present-day distribution and for the NCAR model it is close to the 90th percentile.

3. There is evidence that in at least two models there are changes in the timing of the peak season discharge, towards earlier peaks in the case of the CCCMA and MPI models and a later peak in the IPSL model.

4. There are clearly large differences in the sign and magnitude of projected changes across the 7 GCMs. Both CCCMA and NCAR demonstrate a substantial increase in runoff throughout the year. HadGEM1 and IPSL show relatively small decreases in runoff whereas MPI generates flows that are very similar to the baseline period. HadCM3 and CSIRO GCMs are very similar to each other and suggest a large reduction in runoff throughout the year with little change in the shape of the seasonal distribution. Clearly, the use of a multimodel ensemble mean change would not be a useful indicator of likely climate changes in this case. The range in projected magnitude of changes is greater than that reported by Andersson et al. (2006) using a smaller set of GCMs, which indicated a consistent decline in river discharge by the second half of the 21 st century. The results presented here for a $2{ }^{\circ} \mathrm{C}$ global warming, roughly projected to occur around 2065 for the IPCC SRES A2 scenario, show that uncertainty in the sign and magnitude of river flow remains large. This suggests that the previous studies of Andersson et al. (2006) may have underestimated the magnitude and uncertainty of potential future changes to the basin. 
5. The HadCM3 results for progressive warming levels up to $6^{\circ} \mathrm{C}$ (Fig. 10) suggest extreme impacts with an almost complete loss of the wet season runoff peaks for $4^{\circ} \mathrm{C}$ warming or greater.

6. The influence of hydrological model parameter uncertainty as represented here is not trivial and leads to uncertainty of up to about $10 \%$ in peak season magnitude. Nevertheless, uncertainty associated with climate models dominates the grand ensemble envelope. It is therefore very clear that the uncertainty in future runoff variations, based on the consideration of several GCM predictions, is far greater than the uncertainty in the calibration and application of the hydrological model.

Table 2 illustrates the effects of changing the approach for estimating time series variations in potential evaporation from the simple method discussed above to the use of the Hargreaves estimation equation. The values are based on the mean hydrological parameter ensemble for Mukwe in all cases. The Hargreaves method always generates greater runoff (through lower evaporative demand values) and for all of the GCMs, except NCAR, the difference in the climate change signal (relative to the baseline period) is less than $5 \%$. The differences in mean monthly flow between the upper and lower extremes of the simulation ensemble is approximately $7 \%$, suggesting that the uncertainty in the evaluation of appropriate model parameter values is generally greater than the uncertainty in the estimation of potential evaporation variations. This result is almost certainly associated with the fact that actual evaporation losses are affected by moisture availability as much as by atmospheric evaporative demand. Mean annual potential evaporation varies from 1900 to $2500 \mathrm{~mm}$ whereas rainfall varies from approximately $1200 \mathrm{~mm}$ to less than $650 \mathrm{~mm}$ even under the higher rainfall NCAR scenario.

\section{Conclusions and implications for water resource management}

This paper presents results of the most comprehensive study conducted to date on the potential impact of future climate change on river discharge in the Okavango River. The Okavango is one of southern Africa's major rivers and is a major natural resource for human water supply and maintains a rich and important ecological function throughout the basin and notably within the delta wetland region. This study differs from the previous works of Andersson et al. (2006), Folwell et al. (2006) and Murray-Hudson et al. (2006), in that a more comprehensive consideration of uncertainty is developed and the focus is on the effects associated with a $2{ }^{\circ} \mathrm{C}$ global warming scenario, the widely accepted target informing negotiations to limit global emission of greenhouse gases. Given that the likelihood of restricting global warming to this level is receding we can logically consider that the magnitude of climate impacts simulated in this study are at the lower end of what might be considered likely by the second half of the 21 st century. In this context therefore it is important to note the large projected changes to mean river flow as well as the high uncertainty. Both the magnitude and range of projected changes are greater than in previous studies of Andersson et al. (2006) and Folwell et al. (2006). The projected changes across GCMs nearly straddle zero such that using a multi-model ensemble mean as an indicator of climate change would not be appropriate in this case and would give a misleading measure of the possible climate change signal. It is important to recognize that the GCM data used in this study do not represent the full probability space of all possible climate change effects. Until more information is available about the probabilities of different changes it is considered appropriate to report on the full range of ensembles.

Regarding climate change impacts on the Okavango delta, Wolski et al. (2006) note that these are a function of impacts on the upstream hydrology and thus river inflows, rather than of climate changes locally in the delta. As such we can conclude that our current best estimate is that there is a relatively high probability of large changes to the extent and duration of inundation within the delta wetland system during the 21 st century, but whose sign is as yet not known with any degree of confidence.

The question then arises as to what can be done to reduce the uncertainty in projections of the future climate, notably that arising from rainfall projections between GCMs, which is the major source of uncertainty here. Schemes to weight GCMs within probabilistic frameworks have been developed (e.g. Tebaldi et al., 2005), based on criteria of convergence with the multi-model projected change and representation of mean climate. Such methods tend to constrain the uncertainty envelope towards the multi-model mean. There is evidence from seasonal climate prediction that the multi-model mean has greater predictive skill than individual models and that this can inform and "calibrate" climate change projections (Palmer et al., 2008). However, recent studies have indicated that the climate processes that drive variability and longer climate change are different (Biasutti et al., 2008). Therefore, until climate models are understood in terms of the physical "processes" by which they generate their projected changes such methods of model weighting remain essentially untested.

Indeed the issue of climate variability is particularly pertinent to the Okavango River, as the system exhibits a high degree of interannual and multi-annual variability, such that the people and ecology are relatively robust in the face of variability. In about half of the scenarios studied here the change in mean annual flow does not exceed the standard deviation over the 30 year historical period. Whilst the study method adopted here accounts for future changes in rainfall variability over the basin as simulated by the climate models, it is doubtful that the climate models represent this adequately, 
especially the multi-decadal components. As such, there is a clear need to further understand the nature of historical variability and its representation in climate models.

Moreover, further work should focus on the relationship of hydro-climate variability/change and ecological function within important hydro-ecological systems in the delta and upstream region e.g. the BIOKAVANGO ${ }^{1}$ and ACCORD $^{2}$ projects. This is necessary to develop models to simulate the ecological impact of climate change (e.g. Murray-Hudson et al., 2006) to inform management decisions. When considering how to define minimum environmental flows into the delta, for example, we recommend that consideration be given to the ecological impact of a multi-annual to decadal period of low rainfall and river flow occurring under a drying climate change scenario. Currently, the critical thresholds in the river flow distribution that sustain particular ecological functions in the riverine and wetland ecosystems are unknown.

Ongoing initiatives to develop an integrated river basin water management plan through the OKACOM tri-nation commission should be aware of the magnitude of projected changes and the degree of uncertainty. Management plans which attempt to quantify impacts of development interventions should take these results into account when evaluating trade-offs between competing demands within the basin. There is a need for further work to improve the science basis for inputs into the decision making process. At the same time emphasis should be placed on devising "no-regrets" development interventions which are robust in the face of deep uncertainty about the future (Pielke, 2009).

Acknowledgements. This work was supported by a grant from the UK Natural and Environmental Research Council (NERC) awarded to the Department of Geography, University College London (Taylor, Todd, Thompson) under the Quantifying and Understanding the Earth System (QUEST) programme (Ref. NE/E001890/1).

Edited by: R. Taylor

\section{References}

Allen, R. G., Pereira, L. S., Raes, D., and Smith, M.: Crop evapotranspiration - guidelines for computing crop water requirements, FAO Irrigation and Drainage Paper 56, FAO, Rome, 1998.

Andersson, L., Gumbricht, T., Hughes, D., Kniveton, D., Ringrose, S., Savenjie, H., Todd, M., Wolk, J., and Wolski, P.: Water Flow Dynamics in the Okavango River Basin and Delta - a prerequisite for the Ecosystems of the Delta, Phys. Chem. Earth, 28, 11651172, 2003.

Andersson, L., Wilk, J., Todd, M. C., Hughes, D. A., Earle, A., Kniveton, D., Layberry, R., and Savenije, H. H. G.: Impact of climate change and development scenarios on flow patterns in the Okavango River, J. Hydrol., 331, 43-57, 2006.

\footnotetext{
${ }^{1}$ http://www.orc.ub.bw/biokavango

2 http://www2.geog.ucl.ac.uk/ mtodd/accord/index.htm
}

Biasutti, M., Held, I. M., Sobel, A. H., and Giannini, G.: SST Forcings and Sahel Rainfall Variability in Simulations of the Twentieth and Twenty-First Centuries, J. Climate, 21, 3471-3486, 2008.

Beven, K.: A manifesto for the equifinalty thesis, J. Hydrol., 320, 18-36, 2006.

Beven, K. and Freer, J.: Equifinality, data assimilation, and uncertainty estimation in mechanistic modelling of complex environmental systems using the GLUE methodology, J. Hydrol. 249, 11-29, 2001.

Ellery, W. N. and McCarthy, T. S.: Principles for the sustainable utilisation of the Okavango delta ecosystem, Botswana. Biol. Cons., 70, 159-168, 1994.

Folwell, S. and Farquharson, F.: Climate variability and change: hydrological impacts, in: Proceedings of the fifth FRIEND World Conference, Havana, Cuba, November 2006, IAHS Publ., 308, 382-388, 2006.

Green Cross International, The Okavango River Basin. Transboundary Basin Sub Projects: The Okavango, Available from www. gci.ch/GreenCrossPrograms/waterres/pdf/WFP_Okavango.pdf, 2000.

Jury, M.: Climate and weather factors modulating river flows in southern Angola, Int. J. Climatol., 30, 901-908, 2010.

Hughes, D. A., Andersson, L., Wilk, J., and Savenije, H. H. G.: Regional calibration of the Pitman model for the Okavango River, J. Hydrol., 331, 30-42, 2006.

Kapangaziwiri, E. and Hughes, D. A.: Revised physically-based parameter estimation methods for the Pitman monthly rainfallrunoff model, Water SA 32, 183-191, 2008.

Kingston, D., Todd, M. C., Taylor, R., and Thompson, R. T.: Uncertainty in future freshwater availability associated with the estimation of potential evapotranspiration, Geopyhs. Res. Lett., 36, L20403, doi:10.1029/2009GL040267, 2009.

Legates, D. R. and Willmott, C. J.: Mean seasonal and spatial variability in gauge-corrected, global precipitation, Int. J. Climatol., 10, 111-127, 1990.

Mbaiwa, J. E.: Causes and possible solutions to water resources conflicts in the Okavango River Basin: the case of Angola, Namibia and Botswana,Phys. Chem. Earth, 29, 1319-1326, 2004.

Meehl, G. A., Covey, C., Taylor, K. E., Delworth, T., Stouffer, R. J., Latif, M., McAvaney, B., and Mitchell, J. F. B.: The WCRP CMPI3 multimodel dataset: a new era in climate change research, Bull. Amer. Meteorol. Soc., 88, 1383-1994, 2007.

Mendelsohn, L. and el Obeid, S.: Okavango River, The flow of a lifeline, Struick, Cape Town, South Africa, 2004.

Mitchell, T. D. and Jones, P. D.: An improved method of constructing a database of monthly climate observations and associated high-resolution grids, Int. J. Climatol., 25, 693-712, 2005.

Murray-Hudson, M., Wolski, P., and Ringrose, S.: Scenarios of the impact of local and upstream changes of climate and water use on hydro-ecology in the Okavango Delta, J. Hydrol., 331, 73-84, 2006.

Nash, J. E. and Sutcliffe, J. V.: River flow forecasting through conceptual models, Part I - a discussion of principles, J. Hydrol., 10, 282-290, 1970.

Oudin, L., Perrin, C., Mathevet, T., Andréassian, V., and Michel, C.: Impact of biased and randomly corrupted inputs on the efficiency and the parameters of watershed models, J. Hydrol., 320, 62-83, 
2006.

Palmer, T. N., Doblas-Reyes, F. J., Weisheimer, A., and Rodwell, M. J.: Toward Seamless Prediction: Calibration of Climate Change Projections Using Seasonal Forecasts, Bull. American Met. Soc., 89, 459-470, 2008.

Pielke Jr., R. A.: Collateral Damage from the Death of Stationarity, GEWEX News, 5-7, 2009.

Pinheiro, I., Gabaake, G., and Heyns, P. L.: Cooperation in the Okavango River Basin: the OKACOM perspective, in: Transboundary Rivers, Sovereignty and Development: Hydropolitical Drivers in the Okavango River Basin, African Water Issues Research Unit/Green Cross International/Univ. of Pretoria, edited by: Turton, A., Ashton, P., and Cloete, E., Pretoria, South Africa, 105-118, 2003.

Tebaldi, C. L., Smith, R. L., Nychka, D., and Mearns, L. O.: Quantifying uncertainty in projections of regional climate change: A Bayesian approach to the analysis of multimodel ensembles, J. Climate, 18, 1524-1540, 2005.
Todd, M. C., Taylor, R. G., Osborne, T., Kingston, D., Arnell, N. W., and Gosling, S. N.: Quantifying the impact of climate change on water resources at the basin scale on five continents - a unified approach, Hydrol. Earth Syst. Sci. Discuss., 7, 7485-7519, doi:10.5194/hessd-7-7485-2010, 2010.

Wilk, J., Kniveton, D., Andersson, L., Layberry, R., Todd, M. C., Hughes, D., Ringrose, S., and Vanderpost, C.: Estimating rainfall and water balance over the Okavango River basin for hydrological applications, J. Hydrol., 331, 18-29, 2006.

Wolf, A. T., Yoffe, S. B. and Giordano, M.: International waters: indicators for identifying basins at risk, UNESCO-IHP-VI, Technical Documents in Hydrology, PC-CP Series, No. 20, 30 pp., 2003.

Wolski, P. and Murray-Hudson, M.: Alternative futures of the Okavango Delta simulated by a suite of global climate and hydroecological models, Water SA, 34, 605-610, 2008.

Wolski, P., Savenije, H. H. G., Murray-Hudson, M., and Gumbricht, T.: Modelling of the flooding in the Okavango Delta, Botswana, using a hybrid reservoir-GIS model, J. Hydrol., 331, 58-72, 2006. 